\title{
Sexual bipotentiality of the olfactory pathway for sexual behavior in goldfish
}

\author{
Yu Shinohara ${ }^{1} \cdot$ Makito Kobayashi $^{1}$
}

Received: 30 April 2020 / Accepted: 21 July 2020

(C) The Author(s) 2021, corrected publication 2021

\begin{abstract}
The goldfish Carassius auratus is a gonochoristic fish, but heterotypic sexual behavior can be induced by hormonal treatment in both males and females. Olfaction is essential for gender-typical sexual behavior in both male and female goldfish. Males have a stimulatory olfactory pathway for their sexual behavior. Female sex pheromones elicit male-typical sexual behavior in males. Olfactory blockage by nasal occlusion or olfactory tract section (OTX) stops elicitation of this behavior in males. Females have an inhibitory pathway for their sexual behavior. Female-typical sexual behavior is triggered by prostaglandin (PG). Olfactory blockage by nasal occlusion inhibits the sexual behavior of females. However, OTX stops this inhibition, and PG-injected OTX females resume their typical sexual behavior. In the present study, we examined whether these gendertypical olfactory pathways are heterotypic in goldfish to elucidate their brain bisexuality. Male-typical behavior was induced in females by androgen treatment and exposure to a pheromone; however, as in males, this behavior was not elicited when the females underwent nasal occlusion or OTX. Female-typical behavior was induced in males by PG treatment; nasal occlusion suppressed this behavior in males as it did in females. Following OTX, PG-injected males resumed female-typical behavior, as did PG-injected females. These results indicate that both male and female goldfish possess bisexual olfactory pathways for sexual behavior.
\end{abstract}

Keywords Brain sex · Goldfish · Olfactory pathway $\cdot$ Olfactory tract $\cdot$ Sexual behavior

\section{Introduction}

It is well known that sexual differentiation of the brain in birds and mammals occurs due to the organizational effects of gonadal sex steroids during early development (Sakuma 2009; Balthazard et al. 2009; Bao and Swaab 2011, 2012; Maekawa et al. 2013). In sexually mature individuals, gonadal sex steroids produce activational effects on the brain regarding the sexual cycle and certain sexual behaviors. Once sexual differentiation is fixed, the brain sex is irreversible in birds and mammals. Because the brain regulates gender-typical sexual behavior (homotypic behavior) of individuals, sexual behaviors of the opposite sex (heterotypic behavior) do not often occur, even if hormones of the

Makito Kobayashi

makito@icu.ac.jp

1 Department of Natural Sciences, International Christian University, 3-10-2 Osawa, Mitaka, Tokyo 181-8585, Japan opposite sex are administered. However, the brain function of some teleost fish species does not conform to the paradigm of birds and mammals under either field or laboratory conditions (Munakata and Kobayashi 2010; Larson 2011; Goncalves and Oliveira 2011; Kobayashi et al. 2013).

Sex change (sequential and simultaneous hermaphroditism) occurs naturally in certain fish species as their reproductive strategy. Individuals of these species perform the sexual behavior of either sex at some point during their lifetime. Non-sex-changing (gonochoristic) fish normally perform only gender-typical sexual behavior and do not exhibit heterotypic reproductive functions; however, heterotypic sexual behavior can be induced in some species of fish by hormonal treatment (Munakata and Kobayahi 2010; Knapp et al. 2011; Kobayashi et al. 2013; Saoshiro et al. 2013). Thus, it is thought that some species of fish may have a sexually bipotential brain that regulates the sexual behavior of both sexes.

The physiological regulation of sexual behavior in the goldfish Carassius auratus, a small cyprinid, is well 
understood compared with that of other species of fish (Munakata and Kobayashi 2010; Stacey 2011, 2015; Kobayashi et al. 2013). Prostaglandin F2 $\alpha$ (PG), which is produced in the ovary at the time of ovulation, induces female sexual behavior (egg release). PG and its metabolites are released into water as sex pheromones to stimulate male sexual behavior (chasing and sperm release). Ovarian estrogens are not necessary for females to show female-typical sexual behavior. However, testicular androgens are essential for the induction of male-typical behavior (Kobayashi and Stacey 1993; Stacey and Kobayashi 1996). Injection of PG into normal goldfish males elicited female-typical sexual behavior within several minutes, although no egg release occurred in goldfish females following injection with PG (Stacey and Kyle 1983). Females implanted with a capsule of androgen [11-ketotestosterone or methyltestosterone (MT)] showed a response to PG pheromones and exhibited male-typical sexual behavior without actual sperm release a few days after implantation (Stacey and Kobayashi 1996; Saoshiro et al. 2013). Thus, it is thought that administration of PG and androgens to male and female goldfish could easily induce gender-typical and heterotypic sexual behavior.

Olfaction has recently been identified as one of the critical factors for sexual behavior in female goldfish, as well as in male goldfish (Kawaguchi et al. 2014). Male goldfish show stimulatory olfactory regulation, whereas female goldfish show inhibitory olfactory regulation. In males, sexual behavior is known to involve sex pheromones (Stacey 2011, 2015), and PG pheromones released from ovulatory or PG-injected females elicit sexual behavior in them. The sex pheromones reach the olfactory epithelium of the males through the nasal cavity, and then the pheromonal signal is transmitted to the olfactory bulbs by the olfactory nerve (Fig. 1). Pheromonal information is first integrated in the olfactory bulbs and sent to the telencephalon via the olfactory tracts. The neural circuit regulating sexual behavior is known to be located in the area of the ventral telencephalon (Kyle et al. 1982; Koyama et al. 1985; Lastein et al. 2006). The stimulation of olfactory pathways for sexual behavior can be easily examined by blocking olfaction (Kawaguchi et al. 2014) via nasal occlusion or olfactory tract section (OTX). Nasal occlusion blocks the reception of pheromones, whereas OTX blocks the transmission of pheromonal information. Nasal occlusion or OTX inhibits elicitation of sexual behavior in males, even when they are mated with pheromone-releasing females, because of the lack of pheromone-induced stimulation.

In contrast, females show inhibitory olfactory regulation of sexual behavior (Kawaguchi et al. 2014). PG acts on the female brain as a trigger of sexual behavior. Blockage of olfaction by nasal occlusion suppresses sexual behavior even under stimulation by PG. This indicates that olfaction is essential for female sexual behavior. However, an OTX female can perform female-typical behavior following PG

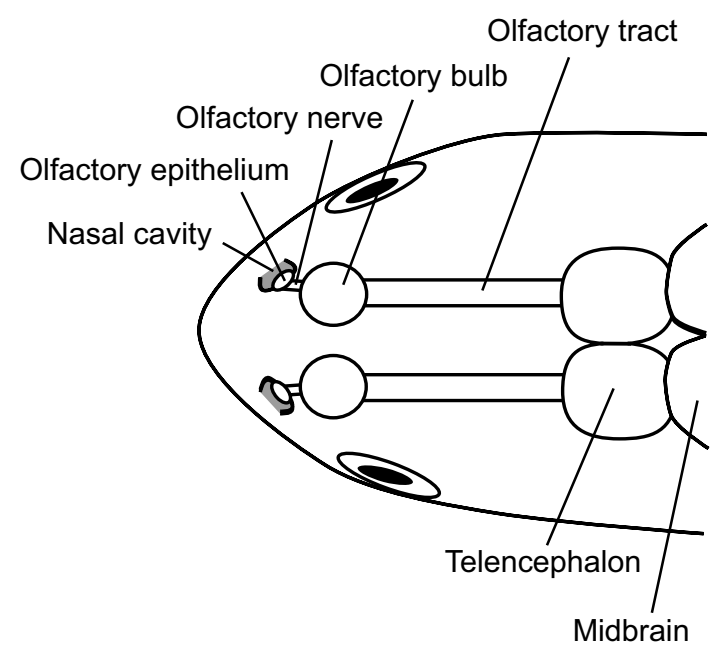

Fig. 1 Schematic presentation of the olfactory pathway of goldfish. Odorants enter the nasal cavity and reach the olfactory epithelium. The olfactory information is transmitted from the olfactory nerve to the olfactory bulbs. The olfactory bulbs transmit impulses via bundles of fibers, the olfactory tracts, to the telencephalon where the neural circuit regulating sexual behavior is located

injection, even though no environmental olfactory information is transmitted to the telencephalon. This indicates that the olfactory bulbs send an inhibitory signal to the telencephalon when olfaction is blocked by nasal occlusion, but as this inhibitory signal cannot be transmitted when the fish undergo OTX, the fish perform female-typical sexual behavior in response to injection with PG. However, the physiological role of the inhibitory regulation of female sexual behavior in the goldfish is unknown.

In the present study, we examined whether these gender-typical olfactory pathways are heterotypic in male and female goldfish to further elucidate the sexual bipotentiality of the brain in this species by coupling two methods of olfactory blockage, nasal occlusion and OTX.

\section{Materials and methods}

\section{Fish}

A common variety of goldfish Carassius auratus was obtained from a fish merchant in Saitama Prefecture, Japan. Approximately 300 fish (males and females) were kept in an 800-1 stock tank maintained at $20{ }^{\circ} \mathrm{C}$ under a 16 -h light/8-h dark (16L/8D) photoperiod (lights on at 0600 hours). The fish were fed with commercial goldfish feed (Comet Goldfish Feed, Itosui, Tokyo) once a day. Sexually mature male and female goldfish weighing 10-50 g were used for the experiments. For the behavior experiments, 20-30 fish were transferred at the same time from stock tanks to 60-1 glass 
acclimation aquaria and kept at $20^{\circ} \mathrm{C}$ under a $16 \mathrm{~L} / 8 \mathrm{D}$ photoperiod over for 1-10 days. Each behavior test was conducted in 60-1 glass observation aquaria equipped with an artificial aquatic plant made of acrylic yarn, gravel, and a box filter. Observation aquaria were maintained at $20{ }^{\circ} \mathrm{C}$ and a $16 \mathrm{~L} / 8 \mathrm{D}$ photoperiod. Behaviorally active fish were selected by preliminary behavior tests by PG injection or by mating with PG-injected females, then used for the experiments. The handling of fish in the present study was approved by the Animal Experimentation Committee of the International Christian University.

\section{Hormonal treatments for the induction of sexual behavior}

A series of natural spawning behaviors in goldfish was described in detail by Munakata and Kobayashi (2010). Briefly, spawning acts (the complete spawning act) are initiated by the arrival of an ovulated female in the floating aquatic vegetation near the surface of the water, where the male follows the female. The female and the male turn on their sides and swim quickly through the vegetation, releasing eggs and sperm. The male is always positioned under the female and in direct contact with her during this act. Then, the male and female flip their tails to mix the spawned eggs and sperm. Another type of spawning of goldfish, called the incomplete spawning act, was also described. It is similar to the complete spawning act except that the fish leave the vegetation without performing gamete release and tail flipping. In the present study, we considered both the complete and incomplete spawning acts as normal behavior and counted them equally.

The induction of spawning behavior in the goldfish was conducted as described by Kawaguchi et al. (2014). Female goldfish intramuscularly injected with PG (Panaseran Hi, Meiji Seika, Tokyo) were induced to perform the female spawning act (egg-releasing act) in the same way as ovulated females in the presence of sexually mature males, although eggs are not released using the former method. Males do not distinguish between ovulated females and PG-injected females and perform the male spawning act (sperm-releasing act). The spawning behavior tests were conducted in 60-1 glass observation aquaria.

For the male-typical sexual behavior tests, experimental males or MT-implanted females were paired with partner females injected with PG at a dose of $10 \mu \mathrm{g}$ PG/ $2 \mu \mathrm{l}$ saline per fish (a high dose was given to strongly stimulate the female) for the induction of spawning behavior just before each behavior test. Experimental fish and partner females were paired in each observation aquarium and spawning acts were counted over a 60 -min period.

For the female-typical sexual behavior test, experimental females and males were injected with PG intramuscularly at a dose of $0.1 \mu \mathrm{g}$ PG/0.1 $\mu$ l saline per g body weight (standard dose per body weight to measure female sexual behavioral activity of each fish) just before each behavior test (Stacey and Kyle 1983; Saoshiro et al. 2013; Kawaguchi et al. 2014). Experimental fish were paired with sexually mature partner males in each observation aquarium, and spawning acts were counted over a 60 -min period.

For the induction of the male-typical spawning act in females, capsules containing MT were prepared and implanted into experimental females as described by Saoshiro et al. (2013). Crystalline MT (25 mg) (SigmaAldrich Japan, Tokyo) was first dissolved in ethanol (500 $\mu$ l) and then mixed with sesame oil $(5 \mathrm{ml})$. After the ethanol had evaporated overnight at room temperature, the MT solution was injected into 20-mm-long silicone tubing ( $\mathrm{SH}$ no.2, Silascon Medical Tube, $2.0 \mathrm{~mm}$ internal diameter, $3.0 \mathrm{~mm}$ outer diameter; Kaneka Medix, Osaka, Japan). The ends of the tubing were sealed with adhesive (KE45T; Shin-Etsu Chemical, Tokyo). Each capsule contained $250 \mu \mathrm{g}$ of MT in $50 \mu \mathrm{l}$ of sesame oil. For implantation of the capsules, an incision approximately $3 \mathrm{~mm}$ long was made on the left side of the body near the anus after the fish had been anesthetized with $0.02 \%$ ethyl 3 -aminobenzoate methanesulfonate salt solution (Sigma-Aldrich). The capsules were inserted into the body cavity through this incision. No sutures were used after the implantation procedure. For individual identification of MT-implanted females, tags (TX-1400L; Destron Fearing, South St. Paul, MN) were inserted into the body cavity. About a month later, when tubercles (a secondary characteristic of male goldfish) were visible on the pectoral fins of these MT-implanted females, they were used for the experiments. Experimental fish without a tag were individually identified by fin clipping.

\section{Blockage of olfaction}

For the blockage of olfaction, two established methods were employed in this study (Kawaguchi et al. 2014): nasal occlusion, which blocks the reception of odorants; and OTX, which blocks the transmission of olfactory information from the olfactory bulb to the telencephalon where the neural circuit controlling sexual behavior is located (Kyle et al. 1982; Koyama et al. 1985).

Nasal occlusion was carried out according to a previously reported method (Partridge et al. 1976; Kawaguchi et al. 2014). Fish were anesthetized by immersion in $0.02 \%$ ethyl 3-aminobenzoate methanesulfonate salt solution (SigmaAldrich). The nasal cavities were occluded with denture fix (Shin-Poligrip-SA Mutenka, Earth Chemical, Tokyo). The fish were then kept in a tank of dechlorinated water for 10-20 min for recovery from anesthesia before the behavior tests. For the complete blockage of olfaction, both nasal cavities were bilaterally occluded. No toxicity of the denture fix 
was observed in fish which underwent unilateral nasal occlusion in our previous study (Kawaguchi et al. 2014). Also, since partial bilateral occlusion with the denture fix did not affect the behavior of fish in a previous study (Kobayashi, unpublished data), the odors of the component compounds of the denture fix were not considered to be involved in the suppression of behavior in the present study. The control fish were not subjected to olfactory blockage. The method of occlusion was effective in blocking olfaction for 70-80 min after the fish recovered from anesthesia since the denture fix used in the present study is water soluble, and some bilaterally occluded males started to show male sexual behavior in the presence of PG-injected females around this time, probably due to leakage of water into the olfactory epithelium. Therefore, the observation period of this experiment was set to $60 \mathrm{~min}$.

OTX was carried out according to a previously described method (Stacey and Kyle 1983; Kobayashi et al. 1986, 1994; Kawaguchi et al. 2014). Fish were anesthetized by immersion in $0.02 \%$ ethyl 3-aminobenzoate methanesulfonate salt solution (Sigma-Aldrich). A three-sided flap was cut into the frontal bone using a disc saw in order to expose the olfactory tracts. After removal of the square flap of the frontal bone, the olfactory tracts were bilaterally sectioned in two places with Wecker scissors, and the resultant sections removed. The cavity resulting from the operation was filled with gelatin sponge (Spongel; Yamanouchi Pharmaceutical, Tokyo). Control fish underwent a sham operation similar to that for OTX but without sectioning of the olfactory tracts. The operated fish were used for the behavior tests on the day following the operation.

\section{Experiment 1: effects of nasal occlusion on male-typical sexual behavior in male and MT-implanted female goldfish}

Kawaguchi et al. (2014) showed that male-typical sexual behavior in male goldfish is triggered by sex pheromone released by females (Fig. 2a), and that males subjected to bilateral nasal occlusion with denture fix did not perform sexual behavior because reception of the pheromone was blocked (Fig. 2b). In addition, Saoshiro et al. (2013) showed that male-typical behavior can be induced in female goldfish by androgen implantation and exposure to PG-injected females (Fig. 2c).

In this experiment, the effects of nasal occlusion on male-typical behavior were compared between male and MT-implanted females to examine whether female goldfish have the same olfactory pathway as males. Experimental males (Fig. 2b) and MT-implanted females (Fig. 2d) underwent bilateral nasal occlusion and were paired with PGinjected partner females after which male-typical sexual behavior was observed. The controls were males (Fig. 2a)

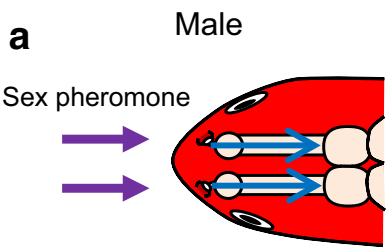

Activation

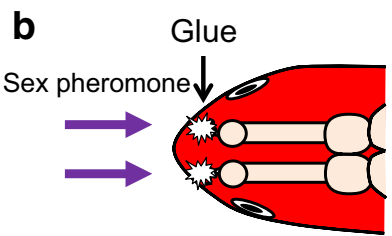

No activation c MT-Female

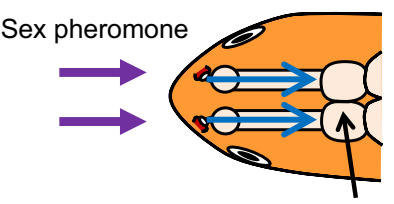

Activation MT

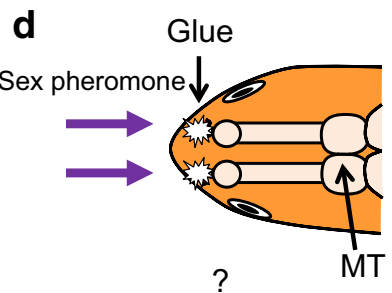

Fig. 2 Design of experiment 1. Effects of nasal occlusion on maletypical behavior were examined in methyltestosterone (MT)implanted female (MT-female) (d) (see text for details)

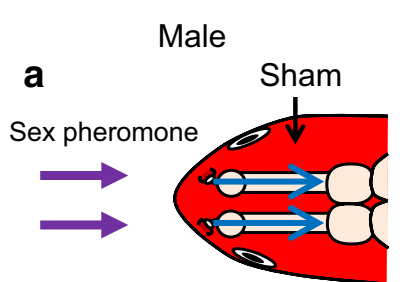

Activation

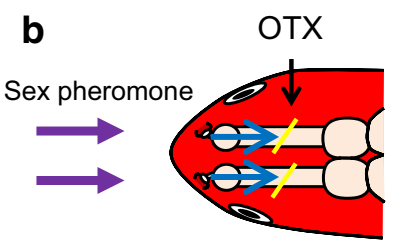

No activation
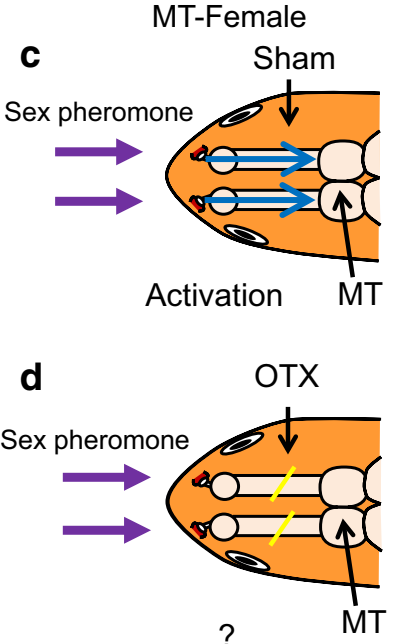

Fig. 3 Design of experiment 2. Effects of olfactory tract section $(O T X)$ on male-typical behavior were examined in MT-females (d) (see text for details). Sham Sham operated; for other abbreviations, see Fig. 2

and MT-implanted females (Fig. 2c) without nasal occlusion paired with PG-injected partner females.

\section{Experiment 2: effects of OTX on male-typical sexual behavior in male and MT-implanted female goldfish}

Kawaguchi et al. (2014) showed that male-typical sexual behavior in male goldfish is triggered by sex pheromone released by females (Fig. 3a), and that males that underwent OTX did not perform sexual behavior because the transmission of pheromone-specific information from the olfactory 
bulb to the telencephalon was blocked (Fig. 3b). In addition, Saoshiro et al. (2013) showed that male-typical behavior can be induced in female goldfish by androgen implantation and then exposure to PG-injected females (Fig. 3c).

In this experiment, the effects of OTX on male-typical behavior were compared between males and MT-implanted females to examine whether female goldfish have the same olfactory pathway as males. Experimental males (Fig. 3b) and MT-implanted females (Fig. 3d) underwent OTX. On the following day, they were paired with PG-injected partner females and male-typical sexual behavior observed. The controls were sham-operated males (Fig. 3a) and shamoperated MT-implanted females (Fig. 3c) paired with PGinjected partner females.

\section{Experiment 3: effects of nasal occlusion on female-typical sexual behavior in PG-injected female and male goldfish}

Kawaguchi et al. (2014) showed that female-typical sexual behavior in female goldfish is triggered by PG injection (Fig. 4a), and that female-typical sexual behavior, mediated by an inhibitory olfactory pathway, is suppressed by bilateral nasal occlusion with denture fix even under stimulation with PG (Fig. 4b). In addition, Saoshiro et al. (2013) showed that female-typical behavior can be induced in males by PG injection (Fig. 4c).

In this experiment, the effects of nasal occlusion on female-typical behavior were compared between PGinjected females and PG-injected males to examine whether male goldfish have the same olfactory pathway as females. Experimental females (Fig. 4b) and males (Fig. 4d) underwent bilateral nasal occlusion, were injected with PG, and paired with sexually mature partner males, after which female-typical sexual behavior was observed. The controls were PG-injected females (Fig. 4a) and PG-injected males (Fig. 4c) without nasal occlusion paired with sexually mature partner males.

\section{Experiment 4: effects of OTX on female-typical sexual behavior in PG-injected female and male goldfish}

Kawaguchi et al. (2014) showed that female-typical sexual behavior in female goldfish was triggered by PG injection (Fig. 5a), and that females that underwent OTX resumed sexual behavior because there was no inhibitory signal from the olfactory bulb to the telencephalon (Fig. 5b). In addition, Saoshiro et al. (2013) showed that female-typical behavior can be induced in males by PG injection (Fig. 5c).

In this experiment, the effects of OTX on female-typical behavior were compared between PG-injected females and PG-injected males to examine whether male goldfish have the same olfactory pathway as female goldfish. Experimental females (Fig. 5b) and males (Fig. 5d) underwent OTX. On the following day, they were injected with PG and paired with sexually mature partner males, then female-typical sexual behavior was observed. The controls were sham-operated females (Fig. 5a) and sham-operated males (Fig. 5c) injected with $\mathrm{PG}$ and paired with sexually mature partner males. a

PG-Female

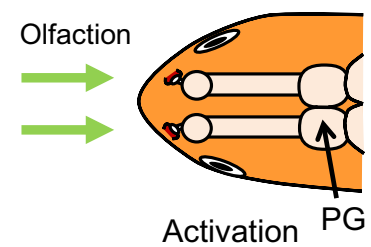

b

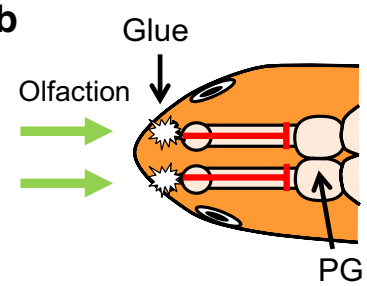

Suppression
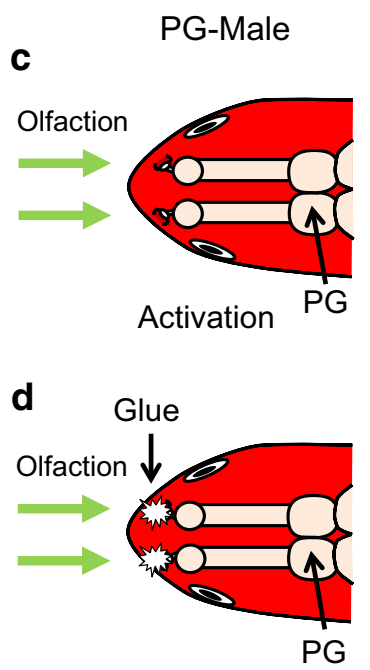

$?$
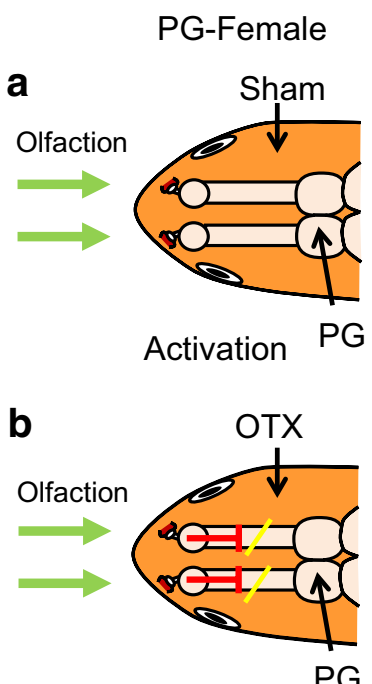

No suppression

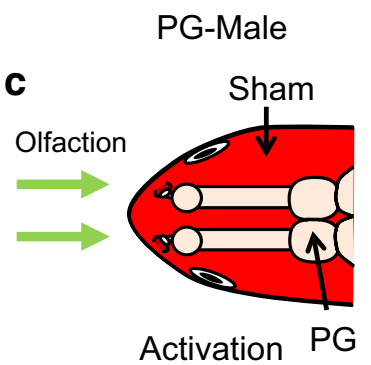

d

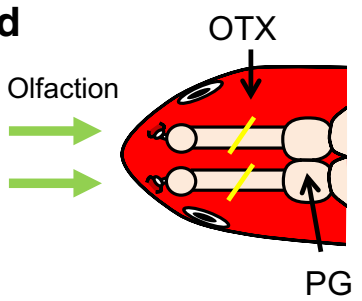

$?$
Fig. 4 Design of experiment 3. Effects of nasal occlusion on femaletypical behavior were examined in prostaglandin (prostaglandin $\mathrm{F} 2 \alpha$; PG)-injected males (PG-Male) (d) (see text for details). PG-Female PG-injected female; for other abbreviations, see Fig. 2
Fig. 5 Design of experiment 4. Effects of OTX on female-typical behavior were examined in PG-injected males (d) (see text for details). For abbreviations, see Figs. 3 and 4 


\section{Statistical analysis}

Group data were compared by Student's $t$-test (https://www. gen-info.osaka-u.ac.jp/MEPHAS/t-ken.html) or Welch's $t$-test (https://www.gen-info.osaka-u.ac.jp/MEPHAS/welch .html) depending on the variance of the data. The level of statistical significance was 0.05 for both statistical tests.

\section{Results}

\section{Experiment 1: effects of nasal occlusion on male-typical sexual behavior in male and MT-implanted female goldfish}

Control males and control MT-implanted females actively performed male-typical sexual behavior. Levels of sexual behavior in bilaterally occluded males and bilaterally occluded MT-implanted females were significantly lower than in the respective control fish $(P<0.05)$ (Fig. 6).

\section{Experiment 2: effects of OTX on male-typical sexual behavior in male and MT-implanted female goldfish}

Control males (sham operated) and control MT-implanted females (sham operated) actively performed male-typical sexual behavior. Levels of sexual behavior in OTX males and OTX MT-implanted females were significantly lower than those of respective control fish $(P<0.05)$ (Fig. 7).

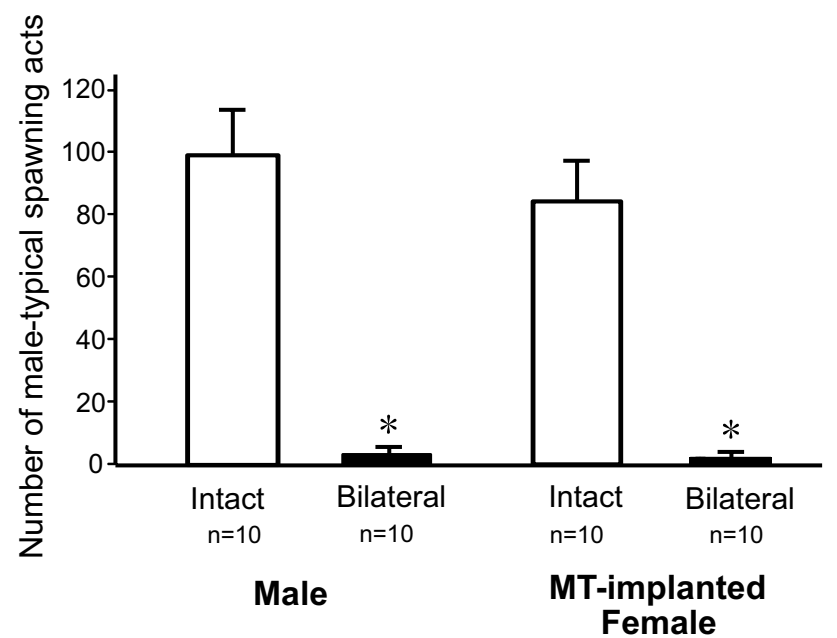

Fig. 6 Effects of nasal occlusion on male-typical sexual behavior in male and MT-implanted female goldfish (experiment 1). Columns represent the mean, bars the SEM. Intact No nasal occlusion, Bilateral bilateral nasal occlusion, MT-implanted female females implanted with a silicone capsule containing MT for the induction of male-typical behavior. * $P<0.05$ (statistically significant difference compared to intact fish)

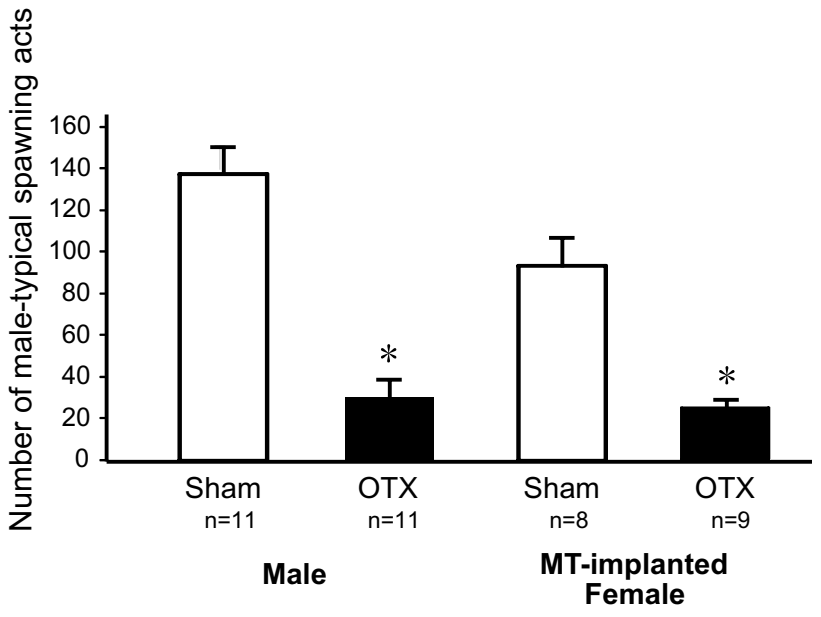

Fig. 7 Effects of OTX on male-typical sexual behavior in male and MT-implanted female goldfish (experiment 2). Columns represent the mean, bars the SEM. $* P<0.05$ (statistically significant difference compared to sham-operated fish). For abbreviations, see Figs. 2, 3 and 6

\section{Experiment 3: effects of nasal occlusion on female-typical sexual behavior in PG-injected female and male goldfish}

Control females (PG-injected) and control males (PGinjected) actively performed female-typical sexual behavior. Levels of sexual behavior in bilaterally occluded females (PG-injected) and bilaterally occluded males (PG-injected) were significantly lower than in the respective control fish $(P<0.05)$ (Fig. 8).

\section{Experiment 4: effects of OTX on female-typical sexual behavior in PG-injected female and male goldfish}

Sham-operated control females (PG-injected) and shamoperated control males (PG-injected) actively performed female-typical sexual behavior. OTX females (PG-injected) and OTX males (PG-injected) also actively performed female-typical sexual behavior. Levels of sexual behavior in OTX females and OTX males were not significantly different than those of the respective control fish (Fig. 9) $(P>0.05)$.

\section{Discussion}

The present study clearly demonstrated that both male and female goldfish possess the male-typical simulatory and the female-typical inhibitory olfactory pathways for the regulation ofsexual behaviour (Fig. 10). Behavioral experiments in previous studies indicated the existence of sexual bipotentiality of the goldfish brain (Stacey and Kyle 1983; Stacey 


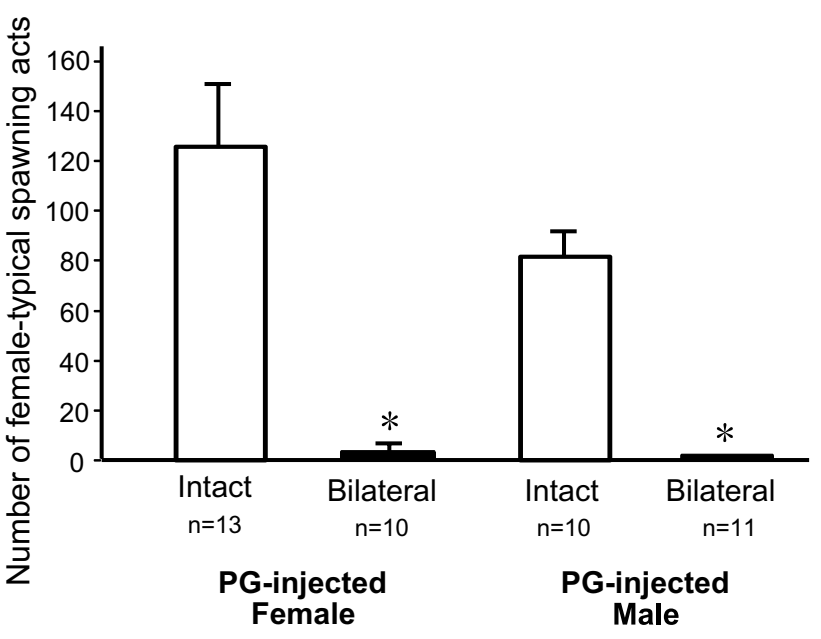

Fig. 8 Effects of nasal occlusion on female-typical sexual behavior in PG-injected female and male goldfish (experiment 3). Columns represent the mean, bars the SEM. PG-injected Female Female fish injected with PG for the induction of female-typical behavior, $P G$ injected Male male fish injected with PG for the induction of femaletypical behavior. $* P<0.05$ (statistically significant difference compared to intact fish). For abbreviations, see Figs. 4 and 6

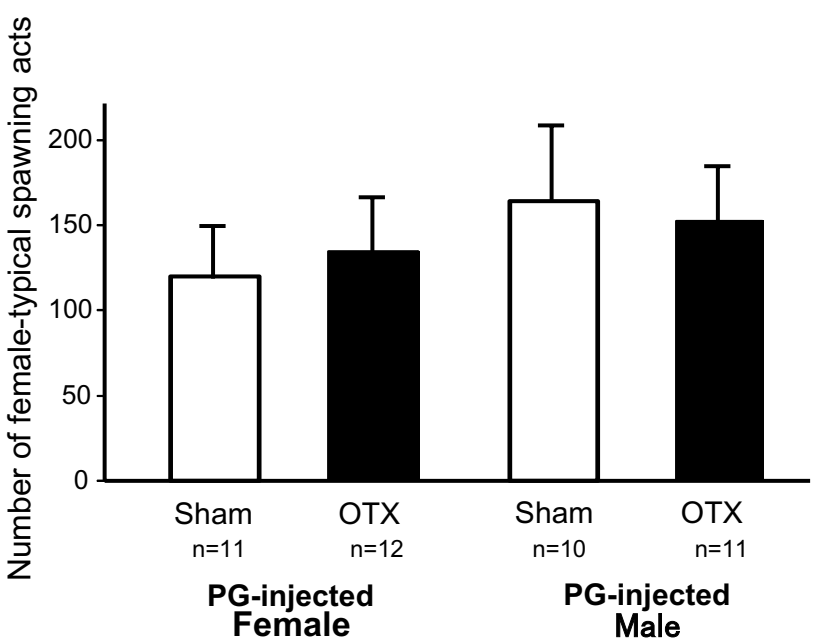

Fig. 9 Effects of OTX on female-typical sexual behavior in PGinjected female and male goldfish (experiment 4). Columns represent the mean, bars the SEM. $P>0.05$ (no statistically significant difference in sexual behavior between sham-operated and OTX fish for both males and females). For abbreviations, see Figs. 4 and 8

and Kobayashi 1996; Saoshiro et al. 2013), but the present study provides experimental evidence of the bipotentiality of the goldfish brain for sexual behavior.

MT-implanted females performed male-typical sexual behavior, but this behavior was not elicited following olfactory blockage, i.e., nasal occlusion and OTX, as it was in males, because of the lack of pheromonal stimulation. These results indicate that female goldfish have the male-typical
Male

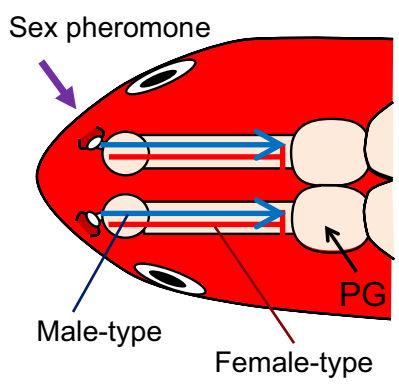

Female

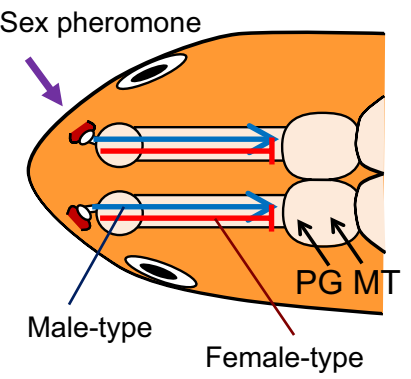

Fig. 10 Sexual bipotentiality of the olfactory pathway for sexual behavior in goldfish. The present study demonstrated that male and female goldfish possess sexually bipotential olfactory pathways for the regulation of sexual behavior. The stimulatory pathway for maletypical behavior (Male-type) is indicated by blue arrows, and the inhibitory pathway for female-typical behavior (Female-type) by red $t$-bars. Both male- and female-type olfactory pathways function in male and female goldfish, even after sexual maturation. For abbreviations, see Figs. 2 and 4

sensory (olfactory) pathway, which functions in response to sex pheromones for the exhibition of male-typical behavior. A recent electrophysiological study by Ghosal and Sorensen (2016) showed that olfactory sensitivity to the PG pheromone can be completely masculinized in female goldfish by androgen treatment.

Some males and MT-implanted females showed weak male sexual behavior after nasal occlusion or OTX. These anosmic fish did not show the vigorous chasing seen in intact males in the presence of PG-injected partner females, and they mostly displayed sexual behavior when their partner females rose into the nearby aquatic vegetation. It is thought that anosmic males sometimes show sexual behavior due to visual stimulation when in the presence of females $(\mathrm{N}$. Stacey and P. Sorensen, personal communication), and not due to incomplete olfactory blockage. However, the reason for the higher frequency of male-typical activity in OTX fish than in bilaterally occluded fish is unknown.

PG-injected males performed female-typical sexual behavior, which was suppressed by nasal occlusion as in PGinjected females. It has been reported that this suppression of sexual behavior is removed by OTX in PG-injected females (Kawaguchi et al. 2014). Interestingly, the suppression of sexual behavior was also removed in males, indicating that male goldfish have the female-typical sensory (olfactory) pathway for the inhibition of female-typical sexual behavior.

Observations on heterotypic behavior in male and female goldfish indicate that they are are functionally bisexual in the motor pathways and muscle functions that are involved in their sexual behavior (Kobayashi, personal observation). However, it is not yet clear how neural circuits in the telencephalon regulate the two types of sexual behavior. It is speculated that one neural circuit can regulate two types of 
sexual behavior or that two discrete circuits regulate respective behaviors. It is also puzzling as to why female goldfish have an inhibitory olfactory system for sexual behavior (Kawaguchi et al. 2014).

The biological significance of the involvement of olfaction in female-typical sexual behavior of goldfish remains to be elucidated. One possible explanation is that the female goldfish searches for an appropriate site for oviposition using olfaction. Normally, females, not males, decide the site of oviposition, and female goldfish need to select water of adequate quality to secure development of the embryos. When olfaction is blocked, female goldfish are unable to examine the quality of water for spawning, and thus their sexual behavior is inhibited. Our recent study showed that the number of spawning acts of PG-injected goldfish significantly declined when a skin extract of goldfish, which may contain an alarm substance (Frisch 1938; Jesuthasan and Mathuru 2009), was added to the water of the experimental aquaria (Kobayashi, unpublished data). Taken together, these results suggest that female goldfish use olfaction when searching for appropriate sites for spawning.

In the present study, we showed that male and female goldfish have a dual olfactory system for sexual behavior, which is stimulatory in the former and inhibitory in the latter. This suggests the interesting question: do other sexchanging fish and non-sex changing fish that can perform heterotypic behavior on hormonal treatment have this type of dual olfactory system?

Acknowledgements We are grateful to Prof. Naoyuki Yamamoto of Nagoya University, Prof. Ryosuke Fujinuma of the International Christian University, and Dr. Clyde S. Tamaru of the University of Hawaii for critical reading of the manuscript. We also thank two anonymous reviewers for valuable comments on the manuscript.

Funding Funded by International Christian University with Grant number AY 2017-NS-BIO-001.

Open Access This article is licensed under a Creative Commons Attribution 4.0 International License, which permits use, sharing, adaptation, distribution and reproduction in any medium or format, as long as you give appropriate credit to the original author(s) and the source, provide a link to the Creative Commons licence, and indicate if changes were made. The images or other third party material in this article are included in the article's Creative Commons licence, unless indicated otherwise in a credit line to the material. If material is not included in the article's Creative Commons licence and your intended use is not permitted by statutory regulation or exceeds the permitted use, you will need to obtain permission directly from the copyright holder. To view a copy of this licence, visit http://creativecommons.org/licenses/by/4.0/.

\section{References}

Adkins-Regan E (2012) Hormonal organization and activation: evolutionary implications and questions. Gen Comp Endocrinol 176:279-285
Balthazart J, Cornil CA, Charlier TD, Taziaux M, Ball GF (2009) Estradiol, a key endocrine signal in the sexual differentiation and activation of reproductive behavior in quail. J Exp Zool 311A:323-345

Bao AM, Swaab DF (2011) Sexual differentiation of the human brain: relation to gender identity, sexual orientation and neuropsychiatric disorders. Front Neuroendocrinol 32:214-226

von Frisch K (1938) Zur Psychologie des Fisch-schwarmes. Naturwissenschaften 26:601-606

Ghosal R, Sorensen PW (2016) Male-typical courtship, spawning behavior, and olfactory sensitivity are induced to different extents by androgens in the goldfish suggesting they are controlled by different neuroendocrine mechanisms. Gen Comp Endocrinol 232:160-173

Goncalves DM, Oliveira RF (2011) Hormones and sexual behavior of teleost fishes. In: Norris DO, Lopez KH (eds) Hormones and reproduction of vertebrates, vol 1. Fishes. Academic Press (Elsevier), New York, pp 119-147

Jesuthasan SL, Mathuru AS (2009) The alarm response in zebrafish: innate fear in a vertebrate genetic model. J Neurogenetics 22:211-228

Kawaguchi Y, Nagaoka A, Kitami A, Mitsuhashi M, Hayakawa Y, Kobayashi M (2014) Gender-typical olfactory regulation of sexual behavior in goldfish. Front Neurosci. https://doi. org/10.3389/fnins.2014.00091

Knapp R, March-Matthews EVL, Rosencrans S (2011) Stress hormone masculinizes female morphology and behaviour. Biol Let $7: 150-152$

Kobayashi M, Stacey NE (1993) Prostaglandin-induced female spawning behavior in goldfish (Carassius auratus) appears independent of ovarian influence. Horm Behav 27:38-55

Kobayashi M, Kobayashi M, Aida K, Hanyu I (1986) Pheromone from ovulatory female goldfish induces gonadotropin surge in males. Gen Comp Endocrinol 63:451-455

Kobayashi M, Amano M, Kim M, Furukawa K, Hasegawa Y, Aida K (1994) Gonadotropin-releasing hormones of terminal nerve origin are not essential to ovarian development and ovulation in goldfish. Gen Comp Endocrinol 95:192-200

Kobayashi M, Saoshiro S, Kawaguchi Y, Hayakawa Y, Munakata A (2013) Sexual plasticity of behavior in goldfish. In: Senthilkumaran B (ed) Sexual plasticity and gametogenesis in fishes. Nova Science, New York, pp 183-201

Koyama Y, Satou M, Ueda K (1985) Sexual behavior elicited by electrical stimulation of the telencephalic and preoptic areas in the goldfish, Carassius auratus. Zool Sci 2:565-570

Kyle AL, Stacey NE, Peter RE (1982) Ventral telencephalic lesions: effects on bisexual behavior, activity, and olfaction in the male goldfish. Behavioral Neural Biol 36:229-241

Larson ET (2011) Neuroendocrine regulation of sex-changing fishes. In: Norris DO, Lopez KH (eds) Hormones and reproduction of vertebrates, vol 1. Fishes. Academic Press (Elsevier), New York, pp 149-168

Lastein S, Hamadani EH, Doving KB (2006) Gender distinction in neural discrimination of sex pheromones in the olfactory bulb of crucian carp, Carassius carassius. Chem Sense 31:69-77

Maekawa F, Sakurai M, Yamashita Y, Tanaka K, Haraguchi S, Yamamoto K, Tsutsui K, Yoshioka H, Murakami S, Tadano R, Goto T, Shiraishi J, Tomonari K, Oka T, Ohara K, Maeda T, Bungo T, Tsudzuki M, Ohki-Hamazaki H (2013) A genetically female brain is required for a regular reproductive cycle in chicken brain chimeras. Nat Commun. https://doi.org/10.1038/ncomm s2372

Munakata A, Kobayashi M (2010) Endocrine control of sexual behavior in teleost fish. Gen Comp Endocrinol 165:456-468

Partridge BL, Liley NR, Stacey NE (1976) The role of pheromones in the sexual behavior of the goldfish. Anim Behav 24:291-299 
Sakuma Y (2009) Gonadal steroid action and brain sex differentiation in the rat. J Neuroendocrinol 21:410-414

Saoshiro S, Kawaguchi Y, Hayakawa Y, Kobayashi M (2013) Sexual bipotentiality of behavior in male and female goldfish. Gen Comp Endocrinol 181:265-270

Stacey NE (2011) Hormonally derived sex pheromones in fishes. In: Norris DO, Lopez KH (eds) Hormones and reproduction of vertebrates, vol 1. Fishes. Academic Press (Elsevier), New York, pp 169-192

Stacey N (2015) Hormonally derived pheromones in teleost fishes. In: Sorensen PW, Wisenden BD (eds) Fish pheromones and related cues. Wiley-Blackwell, Hoboken, pp 33-88
Stacey NE, Kyle AL (1983) Effects of olfactory tract lesions on sexual and feeding behavior in the goldfish. Physiol Behav 30:621-628

Stacey NE, Kobayashi M (1996) Androgen induction of male sexual behaviors in female goldfish. Horm Behav 30:434-445

Publisher's Note Springer Nature remains neutral with regard to jurisdictional claims in published maps and institutional affiliations. 